\title{
Thermoplastic Polyurethane Elastomer Nanocomposites: Morphology, Thermophysical, and Flammability Properties
}

\author{
Wai K. Ho, Joseph H. Koo, and Ofodike A. Ezekoye \\ Department of Mechanical Engineering, The University of Texas at Austin, Austin, TX 78712-0292, USA \\ Correspondence should be addressed to Joseph H. Koo, jkoo@mail.utexas.edu
}

Received 4 May 2009; Revised 13 January 2010; Accepted 11 February 2010

Academic Editor: Xiaogong Wang

Copyright () 2010 Wai K. Ho et al. This is an open access article distributed under the Creative Commons Attribution License, which permits unrestricted use, distribution, and reproduction in any medium, provided the original work is properly cited.

\begin{abstract}
Novel materials based on nanotechnology creating nontraditional ablators are rapidly changing the technology base for thermal protection systems. Formulations with the addition of nanoclays and carbon nanofibers in a neat thermoplastic polyurethane elastomer (TPU) were melt-compounded using twin-screw extrusion. The TPU nanocomposites (TPUNs) are proposed to replace Kevlar-filled ethylene-propylene-diene-monomer rubber, the current state-of-the-art solid rocket motor internal insulation. Scanning electron microscopy analysis was conducted to study the char characteristics of the TPUNs at elevated temperatures. Specimens were examined to analyze the morphological microstructure during the pyrolysis reaction and in fully charred states. Thermophysical properties of density, specific heat capacity, thermal diffusivity, and thermal conductivity of the different TPUN compositions were determined. To identify dual usage of these novel materials, cone calorimetry was employed to study the flammability properties of these TPUNs.
\end{abstract}

\section{Introduction}

Thermal protection materials are required to protect structural components of space vehicles during the reentry stage, missile launching systems, and solid rocket motors. Koo et al. reported in a series of review papers [1-3] on using polymeric composites as ablative thermal protection systems (TPSs) for a variety of military and aerospace applications. Thermal protection materials such as char forming phenolics and carbon-carbon composites are used for spacecraft heat shields, rocket motor insulation, and rocket nozzle assembly materials.

The introduction of inorganic nanomaterials as additives into polymer systems has resulted in polymer nanostructured materials exhibiting multifunctional, highperformance polymer characteristics beyond what traditional polymer composites possess. Multifunctional features attributable to polymer nanocomposites (PNCs) consist of improved thermal and flame resistance, moisture resistance, decreased permeability, charge dissipation, chemical resistance, and enhanced thermal and electrical conductivity [47]. Through control or alteration of the additives at the nanoscale level, one is able to maximize property enhancement of selected polymer systems to meet or exceed the requirements of current military, aerospace, and commercial applications.

Military interest in using PNCs for ablatives has grown steadily since Vaia et al. [8] examined the ablative performance of polycaprolactam (nylon 6) nanocomposites. A relatively tough, inorganic char forms during the ablation of these PNCs resulting in at least an order-of-magnitude decrease in the mass loss (erosion) rate relative to the neat polymer. This occurs for as little as $2 \mathrm{wt} \%(\approx 0.8 \mathrm{vol} \%)$ exfoliated mica-type layered silicate. The nanoscopic distribution of silicate layers appears to create a uniform char layer that enhances the ablative performance. Patton et al. [9] reported the ablation, mechanical, and thermal properties of vapor grown carbon nanofiber (VGCF)/phenolic resin composites for potential usage in solid rocket motor nozzles. Composites specimens with varying loadings including one sample with rayon carbon fiber plies were prepared and exposed to a plasma torch for 20 seconds with a heat flux of $16.5 \mathrm{MW} / \mathrm{m}^{2}$ at approximately $1650^{\circ} \mathrm{C}$. When fiber loadings increased, mechanical, ablative, and insulative properties improved. 
Koo et al. [10, 11] and Koo and Pilato [12] reported two new classes of PNCs that are lighter and have better erosion and insulation characteristics than current stateof-the-art ablatives. For rocket motor internal insulation [10], thermoplastic elastomers were selected as the base polymer incorporated with nanoclay, VGCF, and polyhederal oligomeric silsesquioxane (POSS). Substantial performance improvement was observed with these thermoplastic elastomer nanocomposites as compared with industry standard Kevlar-filled EPDM material. For rocket nozzle ablative $[11,12]$, nanoclay, VGCF, and POSS were incorporated into a resole phenolic and were impregnated into a rayon carbon fiber to fabricate into polymer matrix composites. The simulated solid rocket motor was employed to test these nanocomposite rocket ablative materials (NRAMs) with an industry standard ablative (MX-4926, a carbon phenolic composite). For the Clay-NRAM group, only the $7.5 \mathrm{wt} \%$ Clay-NRAM has a lower ablation rate than MX-4926. For the CNF-NRAM group, all three CNF loadings have lower ablation rate than MX-4926. For the POSS-NRAM group, all three POSS loadings have lower ablation rate than MX4926. The CNF-NRAM group has the lowest heat-soaked temperature.

A recent review by Koo et al. [13] has shown continued progress in using PNCs for rocket propulsion research. PNCs have been developed to enhance materials' properties for high-temperature applications. The feasibility of using PNCs is clearly demonstrated for rocket motor insulation, rocket nozzle ablatives, carbon/carbon composites, and damage tolerant high-performance epoxy fiber-reinforced composite systems.

Thermoplastic polyurethane elastomer nanocomposites (TPUNs) are a novel class of insulation materials developed by Air Force Research Laboratory (AFRL) that is lighter, exhibits better ablative performance and insulation characteristics, and possesses a more cost-effective manufacturing process than the current material, Kevlar-filled ethylenepropylene-diene-monomer rubber (EPDM). Detailed experimental characterization of the TPUNs is required before these novel materials can be used effectively for a variety of military and commercial applications. The objective of this paper is to study the thermophysical and flammability properties as well as the morphological microstructures of this class of TPUNs at elevated temperatures.

\section{Experimental Approach}

\subsection{Materials}

2.1.1. Polymer Resin. Thermoplastic elastomer (TPE) is a family of rubber-like materials that can be processed and recycled like thermoplastics, unlike conventional vulcanized rubbers. An example of a TPE is PELLETHANE 2102-90A, based on polyester polycaprolactone elastomer. This thermoplastic polyurethane elastomer (TPU) material is manufactured by Dow Plastics. It has the following properties: outstanding abrasion resistance, low-temperature flexibility and impact resistance, resistance to fuels, oils, and most nonpolar solvents, hydrolytic stability, range of hardness, low-compression set, high compressive strength, low gas/vapor permeability, relatively high moisture vapor transmission rates, easy processibility with conventional extrusion and thermoplastic molding techniques, and low extractable levels.

2.1.2. Nanoparticles. Two types of nanoparticles, nanoclay and carbon nanofibers (CNFs), were used. Southern Clay Products' montmorillonite (MMT) nanoclay, Cloisite 30B (a natural MMT modified with an organic modifier, MT2EtOT: methyl-tallow-bis-2-hydroxyethylquaternary ammonium at $90 \mathrm{meq} / 100 \mathrm{~g}$ ), was selected [14]. Achieving exfoliation of organomontmorillonite in various continuous phases is a function of the surface treatment of the MMT clays and the mixing efficiency of the dispersing equipment. Surface treatment of MMT is conveniently accomplished with the exchange of inorganic counterions, for example, sodium and so forth, with quaternary ammonium ions. The second type of nanoparticles used was Pyrograf-III PR-19-PS CNFs from Applied Science, Inc. Carbon nanofibers (CNFs) are a form of vapor-grown carbon fibers, which are a discontinuous graphitic filaments produced in the gas phase from the pyrolysis of hydrocarbons [15]. In properties of physical size, performance improvement, and product cost, CNFs complete a continuum bounded by carbon black, fullerenes, and single-wall to multiwall carbon nanotubes on one end and continuous carbon fiber on the other end. PR-19-PS CNF has fiber diameters of 100 to $200 \mathrm{~nm}$ and fiber lengths of 30 to $100 \mu \mathrm{m}$.

2.2. Processing of Polymer Nanocomposites. A $30 \mathrm{~mm}$ Werner Pfleider corotating twin screw extruder which is configured for a wide variety of materials was used for this study. The extruder L/D can be varied from 21 to 48 , with options of multiple feeds and vents. The energy profile of the screw is adjusted to optimally meet the needs of the target product. For the nanoclay, a relatively long residence time is preferred for the screw profile allowing high shear characteristics for complete separation of the nanoclay platelets with the polymer matrix being uniformly dispersed into the clay galleries. For the CNF, the screw was configured to allow separation of the CNF without fracturing them. Separate volumetric feeders were used for the base polymer and the nanoparticles. The TPU, nanoclays, and carbon nanofiber were dried in a desiccant drier overnight before compounding. Injection molded specimens of each blend were prepared and examined by transmission electron microscopy (TEM). In this study, twin-screw extrusion technique was used for blending the 2101-90A TPU with different loading levels of Cloisite 30B nanoclay and PR19-PS CNF. The TPUN formulations, baseline Kevlar-filled EPDM, and pure TPU are listed in Table 1. Approximately $6.75 \mathrm{~kg}$ of each formulation were produced.

\subsection{Measurements}

2.3.1. Morphological Characterization. In our study, WAXD was used on the TPUN-clay specimens. The cross-sections of the TPUN-clay and TPUN-CNF were examined by TEM 
TABLE 1: Material matrix for TPU nanocomposites.

\begin{tabular}{|c|c|c|}
\hline Formulation & $\begin{array}{c}\text { Polymer Matrix } \\
(\mathrm{wt} \%)\end{array}$ & Filler (wt\%) \\
\hline 1 & EPDM $(88 \%)$ & $12 \%$ Kevlar \\
\hline 2 & $2102-90 \mathrm{~A}(100 \%)$ & None \\
\hline 3 & 2102-90A (95\%) & 5\% Cloisite 30B nanoclay \\
\hline 4 & $2102-90 \mathrm{~A}(92.5 \%)$ & 7.5\% Cloisite 30B nanoclay \\
\hline 5 & $2102-90 \mathrm{~A}(90 \%)$ & $10 \%$ Cloisite $30 \mathrm{~B}$ nanoclay \\
\hline 6 & $2102-90 \mathrm{~A}(95 \%)$ & 5\% PR-19-PS CNF \\
\hline 7 & $2102-90 \mathrm{~A}(90 \%)$ & $10 \%$ PR-19-PS CNF \\
\hline 8 & $2102-90 A(85 \%)$ & 15\% PR-19-PS CNF \\
\hline 9 & $2102-90 \mathrm{~A}(80 \%)$ & 20\% PR-19-PS CNF \\
\hline
\end{tabular}

to determine the degree of dispersion of nanoclay/carbon nanofibers within the TPU polymer matrix. Uniform distribution of the nanoparticles within the polymer matrix is essential to yield the best enhancement of material properties of the polymer matrix. Luo and Koo [16] developed a general method to quantify the dispersion of nanoparticles in polymer matrices using TEM analyses. The dispersion quantity, $D$, is defined as the probability of inclusion particle free-path spacing falling into a certain range of the mean spacing $\mu$, according to the particle spacing data frequency distribution. Two quantities, $D_{0.1}$ and $D_{0.2}$, are proposed, which are the probabilities of the particle free-path spacing falling into the ranges of $\mu+0.1 \mu$ and $\mu+0.2 \mu$, respectively. Both normal and lognormal distributions are discussed, and in both cases, the quantities $D_{0.1}$ and $D_{0.2}$ are specified as monotonically increasing functions of $\mu / \sigma$, where $\mu$ and $\sigma$ are the mean particle free-path spacing and standard deviation, respectively. Luo and Koo $[17,18]$ presented the dispersion parameter, $D_{0.1}$, based on the measurement of the free-path spacing distance between the single clay sheets [17], carbon nanofibers, and multiwall carbon nanotubes [18] from the TEM images. This methodology was adapted in our study.

2.3.2. Precharred TPUNs Microstructural Analysis. To examine the characteristics of the precharred TPUNs, the surface and cross-sections were investigated by scanning electron microscopy (SEM) analyses. Two methods were used to obtain charred material. One set of TPUNs was obtained by using a vacuum furnace, heated from room temperature to $400^{\circ} \mathrm{C}$ at heating rate of $400^{\circ} \mathrm{C} /$ hour, maintained at $400^{\circ} \mathrm{C}$ for 5 minutes, and cooled down to room temperature at cooling rate of $200^{\circ} \mathrm{C} /$ hour (method 1). Another set of TPUNs was wrapped in carbon fabric, put into an argon-purging furnace that was preheated at $600^{\circ} \mathrm{C}$, heated for approximately 6.5 minutes, and then removed for inspection (method 2).

In method 1, TPUN specimens were precharred using a vacuum furnace at different temperatures $(200,300$, and $400^{\circ} \mathrm{C}$ ). The furnace chamber was evacuated after loading the samples. Then, the furnace was heated up to the desired precharring temperature at a preset ramp rate (approximately $400^{\circ} \mathrm{C} /$ hour). The samples were heated for 5 minutes isothermally and then cooled at a preset rate (approximately $200^{\circ} \mathrm{C} /$ hour). When the temperature reached below $50^{\circ} \mathrm{C}$, the furnace chamber was purged with nitrogen to break vacuum.

Due to the deficiency of the method 1, the TPUN specimens were given to collaborators at Aerojet for precharring using an argon-purging oven (method 2). First, the specimens $(0.32 \mathrm{~cm}$ thick) were wrapped in a carbon fabric, and the oven was preheated to $600^{\circ} \mathrm{C}$. Then, samples were loaded into the oven and heated at $600^{\circ} \mathrm{C}$ for 5 minutes plus 1.5 minutes of temperature equilibration time ( 6.5 minutes total) with argon flow of $314.6 \mathrm{cc} / \mathrm{second}\left(40 \mathrm{feet}^{3} /\right.$ hour $)$. The presence of argon was critical. When the oven door was opened to remove the sample, the influx of oxygen into the argon-filled chamber caused the carbon-wrapped sample to combust.

2.3.3. Thermophysical Properties Measurements. Thermophysical properties of TPU and TPUNs were evaluated. Density measurement was performed using a pycnometer. Specific heat capacity measurement was performed using a differential scanning calorimeter (DSC). Thermal diffusivity measurement was performed using a laser flash. Thermal conductivity was calculated using data from density, heat capacity, and thermal diffusivity measurements. Thermogravimetric analyses were also conducted to obtain the kinetics of the thermal degradation of these TPUNs and are reported elsewhere $[19,20]$.

Density. True volume of the material was measured using a pycnometer. By measuring the weight of the sample and employing Archimedes's principle of gas displacement and the technique of gas expansion, the density of the sample was obtained.

Specific Heat. Differential scanning calorimetry (DSC) was performed to obtain the specific heat of the TPU and TPUNs. Small amount of material sealed in a pan was heated at a set heating rate in a nitrogen purging environment, and an analyzer recorded the heat flow needed to apply to keep the temperature of the sample pan increasing at the same rate as the reference or empty pan. The specific heat was calculated by dividing the heat flow by the sample weight and the heating rate.

Thermal Diffusivity. Laser flash diffusivity at $45^{\circ} \mathrm{C}$ and $55^{\circ} \mathrm{C}$ was performed to obtain the thermal diffusivity of the TPU and TPUNs. A laser is used to supply a high-intensity, short-duration pulse of thermal energy to one face of a sample. The intensity of the beam was controlled by varying the laser power supply and use of attenuating filters. The resulting temperature rise of the other face of the sample was monitored using an infrared detector. Then, the thermal diffusivity was determined from a numerical analysis of the infrared detector output.

2.3.4. Flammability Studies. Even though these TPUNs were developed mainly for military usage, the authors would like to identify dual usage of these novel materials for commercial markets. Flammability properties of TPU and TPUNs were also evaluated using the cone calorimeter at 


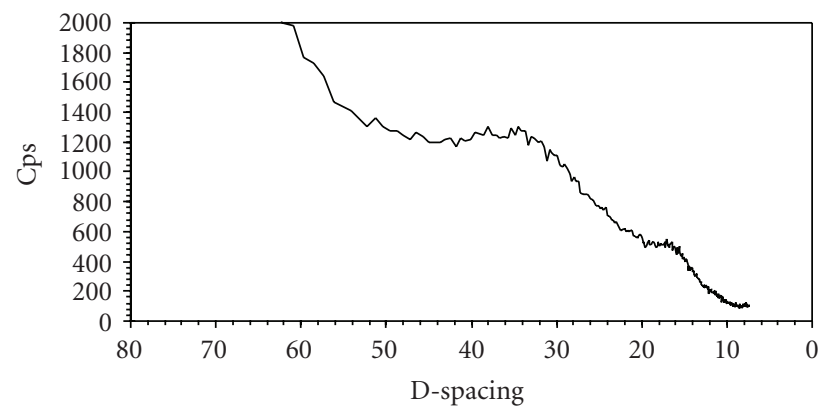

FIGURE 1: Wide-angle X-ray diffraction of 5\% Cloisite 30B nanoclay TPUN.

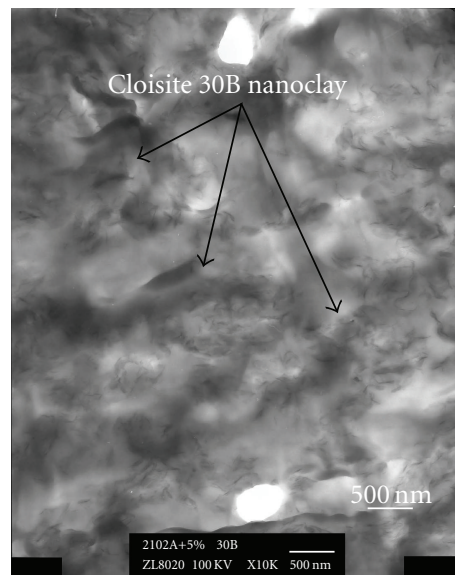

(a)

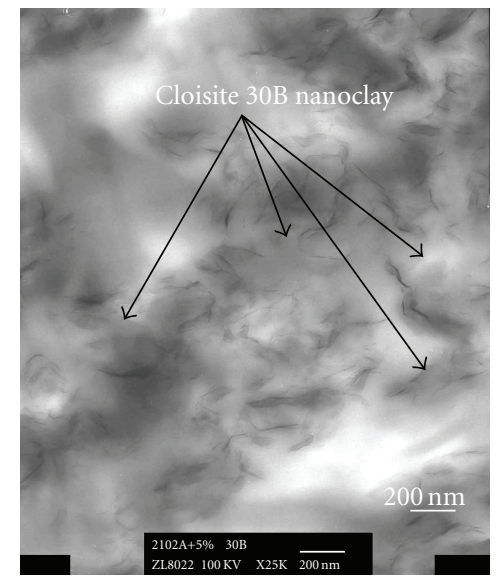

(b)

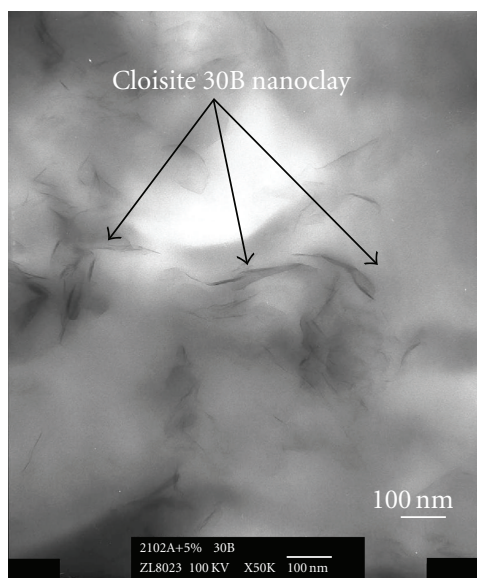

(c)

FIGURE 2: Transmission electron micrographs of 5\% Cloisite 30B nanoclay TPUN in progressive magnifications with unit bars of $500 \mathrm{~nm}$ (a), $200 \mathrm{~nm}(\mathrm{~b})$, and $100 \mathrm{~nm}(\mathrm{c})$.

an external irradiance heat flux of $50 \mathrm{~kW} / \mathrm{m}^{2}$. Average and peak heat release rate, mass loss, carbon monoxide emission, and smoke concentration data were extracted from the experiments. Cone calorimetry test method was followed according to ASTM E1534 standard, "Standard Test Method for Heat and Visible Smoke Release Rates for Materials and Products Using an Oxygen Consumption Calorimeter."

\section{Results and Discussion}

3.1. Morphological Characterization of Polymer Nanocomposites. Selective TPU blends with the baseline Kevlar-filled EPDM were tested using the AFRL Pi-K char motor with aluminized propellants for ablation [21]. The 5\% Cloisite 30B TPUN and 15\% PR-19-PS CNF TPUNs were ranked highest in terms of ablation resistance and mechanical properties for their respective family of nanoparticles, thus chosen for detailed thermophysical properties characterization.

Wide-angle X-ray diffraction (WAXD) was used to analyze all the TPUN-clay specimens. A representative WAXD plot (counts per sec (cps) versus D-spacing) of the 5\% Cloisite 30B TPUN is shown in Figure 1. No large peaks were observed in WAXD, which indicated that the nanoclays were possibly exfoliated in the TPU polymer matrix. In addition, TEM analyses were conducted on all TPUN-clay specimens. Figure 2 shows TEM micrographs in progressive magnifications confirming that the 5\% Cloisite 30B nanoclay achieved exfoliation state in the polymer matrix. A quantification dispersion analyses were also performed using TEM analyses [17] showing exfoliation of nanoclay in the TPU. Transmission electron microscopy analyses were conducted on all TPUN-CNF specimens. A progressive magnification of TEM micrographs of 15\% PR-19-PS CNF TPUN shows uniform dispersion of carbon nanofibers in 2102-90A TPU, as depicted in Figure 3. CNFs of approximately $100 \mathrm{~nm}$ in diameter were fully dispersed in the polymer matrix, forming TPU nanocomposites. A quantification dispersion analyses were also performed using TEM analyses showing welldispersed CNFs in the TPU [18].

\subsection{Microstructural Analysis of Precharred TPUNs}

3.2.1. Precharred TPUNs. There is insufficient data in the literature involving char material properties. The rate of energy storage in a pyrolyzable material is a function of both the density and specific heat of the material in its virgin and char states. In combination with kinetic parameters, accurate values of the thermophysical properties for these two components are necessary to characterize the thermal response of the polymer material [22]. Two methods were 


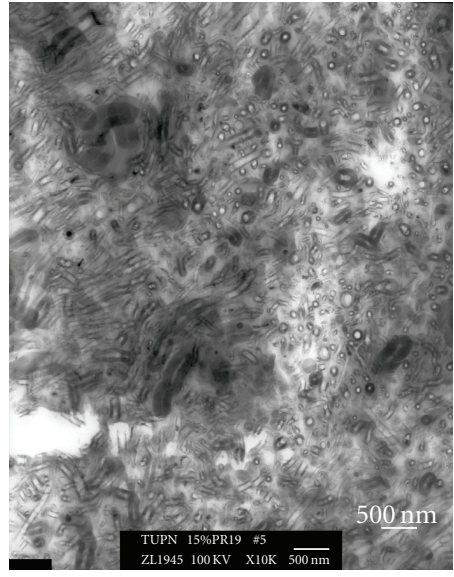

(a)

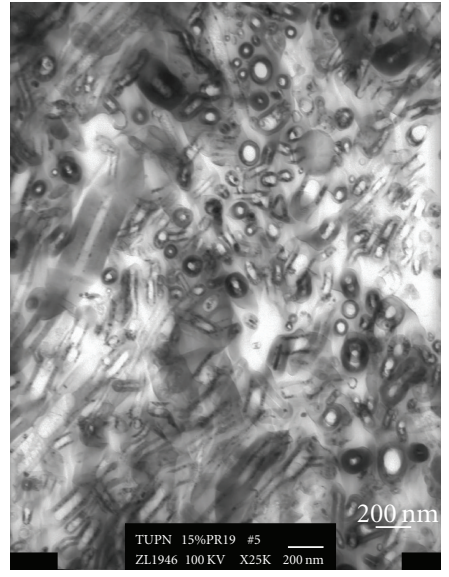

(b)

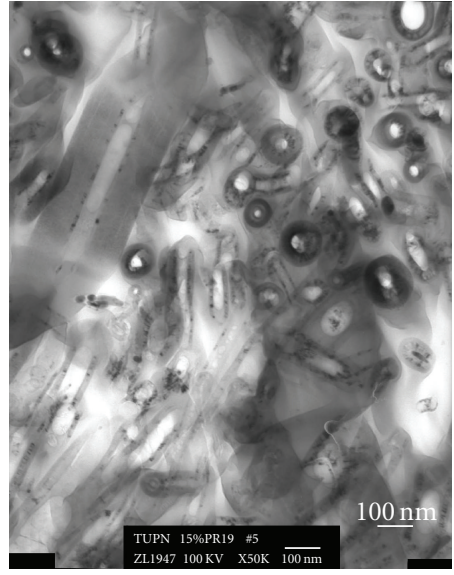

(c)

Figure 3: Transmission electron micrographs of 15\% PR-19-PS CNF TPUN in progressive magnifications with unit bars of $500 \mathrm{~nm}$ (a), $200 \mathrm{~nm}$ (b), and $100 \mathrm{~nm} \mathrm{(c).}$

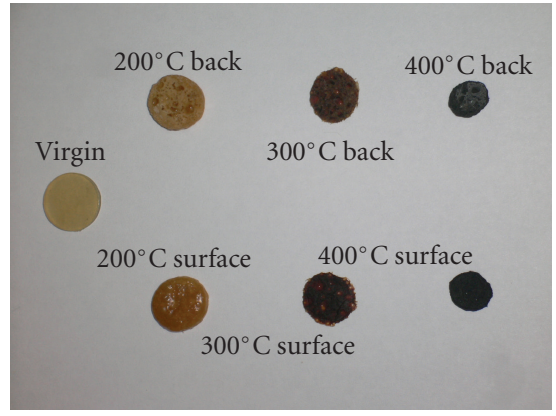

(a)

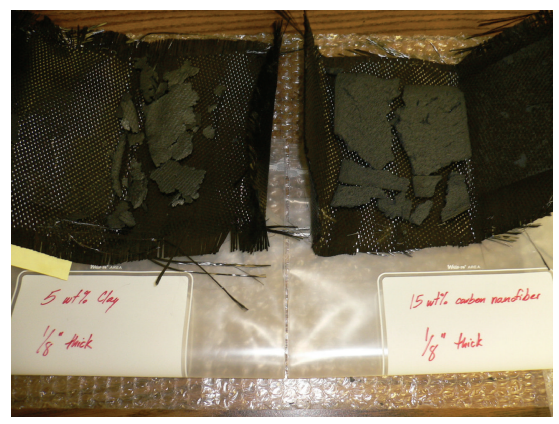

(b)

FIGURE 4: Precharred samples using vacuum furnace (a) and precharred $0.32 \mathrm{~cm}$ thick TPUN plates using argon-purging oven (b).

examined to obtain charred material using a vacuum furnace and an argon-purging oven [23].

Using method 1, the precharred samples, 5\% Cloisite 30B TPUN, are shown in Figure 4(a). From left to right of Figure 4(a) shows the progress of the degree of char formation at elevated temperatures, with the virgin material as the extreme left sample. The top row shows the bottom side of the samples that was rested on top of the furnace chamber, and the bottom row shows the surface of the samples. There are apparent shortcomings to this method. First, the heating rate and cooling rate are too slow. The material was heated to the desired temperature while in a solid rocket motor firing the heating rate is extremely high or almost instantaneous. This indicates that the state of the charred material does not resemble to the posttest specimens obtained from a solid rocket motor firing. Due to the nature of a vacuum furnace, samples cannot be loaded after a desired temperature is reached as well as removed immediately after being heated for specific amount of time. Literature also indicates that char material properties are obtained by precharring the material up to the temperature where it no longer decomposes based on a TGA derivative curve where the weight loss rate is essentially zero [23]. The
$0.32 \mathrm{~cm}$ (1/8-inch) TPUN posttest plates using method 2 are shown in Figure 4(b).

3.2.2. Microstructural Analysis. The mechanisms by which nanoclay and carbon nanofibers reinforced char structures act as insulative layers to protect virgin material can be understood better by examining the microstructures of the precharred samples. Thus, scanning electron microscopy (SEM) was utilized with a JEOL 5610 tungsten-filament scanning electron microscope to study the microstructures. The samples were first coated with gold-palladium using a sputter coater to reduce electron charging, especially for nanoclay-filled samples since they are less electrically conductive. Settings of electron gun and aperture were set at $20 \mathrm{keV}$ of accelerating voltage, $20 \mathrm{~mm}$ of working distance, and 25 of spot size.

The morphological structures of the two sets of precharred samples were analyzed. The first set of samples was wrapped in carbon fabric, put into an argon-purging oven that was preheated to $600^{\circ} \mathrm{C}$, heated, and taken out after 6.5 minutes. Figures 5 and 6 show the micrographs of the surface and cross-sectional views of the $5 \%$ Cloisite 30B TPUN, respectively, at progressive magnifications. On 


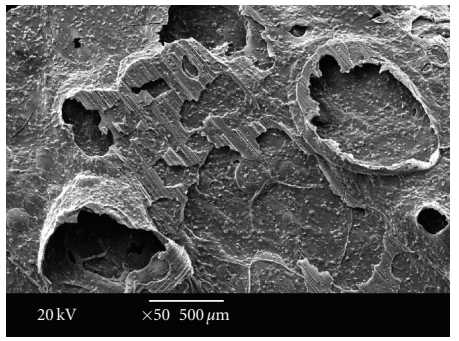

(a)

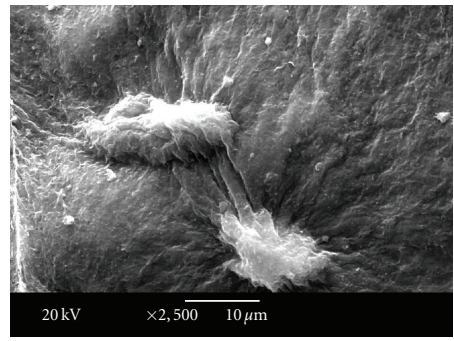

(b)

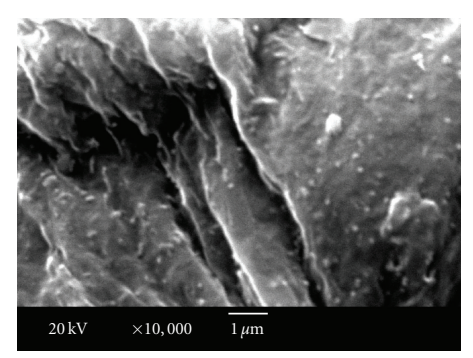

(c)

FigURE 5: Micrographs of 5\% Cloisite 30B TPUN surface in progressive magnifications.

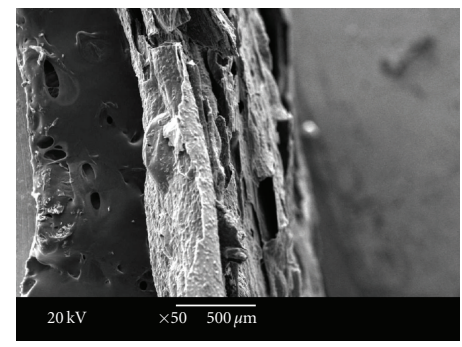

(a)

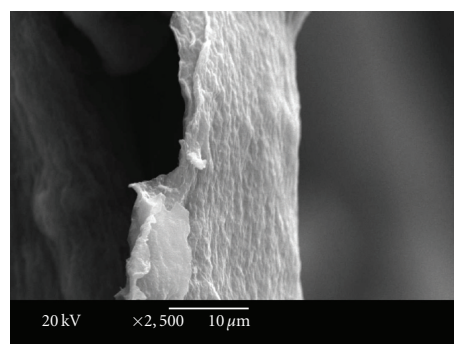

(b)

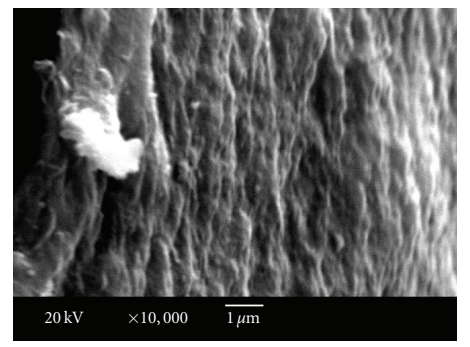

(c)

FIGURE 6: Micrographs of 5\% Cloisite 30B TPUN cross section in progressive magnifications.

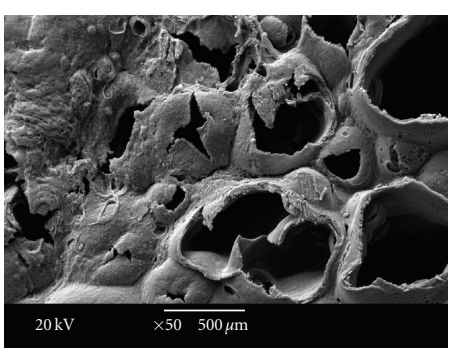

(a)

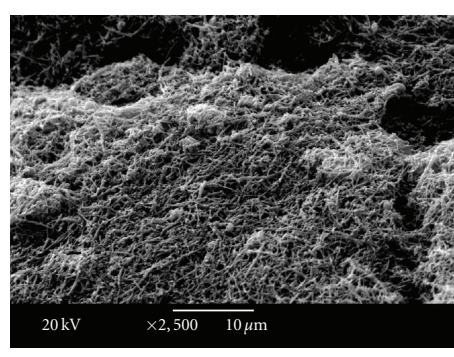

(b)

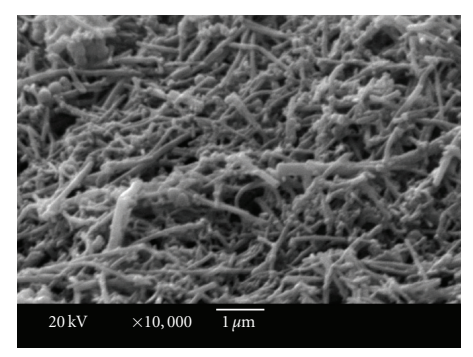

(c)

FIGURE 7: Micrographs of 15\% PR-19-PS TPUN surface in progressive magnifications.

the surface, some flattened fractured bubble traces and relatively spread layers of material were identified, as seen in Figure 5, which signified the protective mechanism of nanoclay. The exfoliated nanoclay platelets formed a ceramic shield-like structure that migrates to the pyrolysis zone when heated to the pyrolysis temperatures. This ceramic shield-like structure insulates the virgin material beneath the pyrolysis zone through the depth of the charred material. Figure 6 shows the micrographs at cross section of $5 \%$ Cloisite 30B TPUN. Micron-size-thick layers are observed which correspond to the ceramic shield-like structure that insulates the virgin material from the heat source.

Figures 7 and 8 show the micrographs of 15\% PR-19-PS TPUN surface and cross section, respectively, in progressive magnifications. On the surface, millimeter-size pores are observed (Figure 7). The resin component degraded and formed gaseous products, and these gaseous products are trapped because of the low porosity and permeability of the material. When the internal pressure becomes sufficiently high, large thermochemical expansion occurs in the solid resin matrix, and the gases diffuse back through the char structures. The gases thus form bubbles on the surface and burst when a critical pore pressure is exceeded. Figure 8 shows the micrographs of the cross section of $15 \%$ PR19-PS TPUN. Similar to the surface, porous structures are identified and networks of CNFs are the residue from the precharring. Since the precharred sample is very porous, the external heat is transferred to the virgin material by these CNFs. In addition, the alignment of the CNFs in the material plays an important role in evaluating its thermal resistance performance. If the CNFs are aligned in the direction of the incident heat flux, heat will be conducted through the material easier and faster.

The second set of samples were obtained using a vacuum furnace, by heating from room temperature to $400^{\circ} \mathrm{C}$ at heating rate of approximately $400^{\circ} \mathrm{C} / \mathrm{hr}$, maintained at $400^{\circ} \mathrm{C}$ 


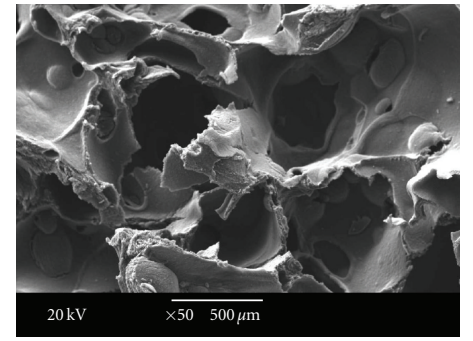

(a)

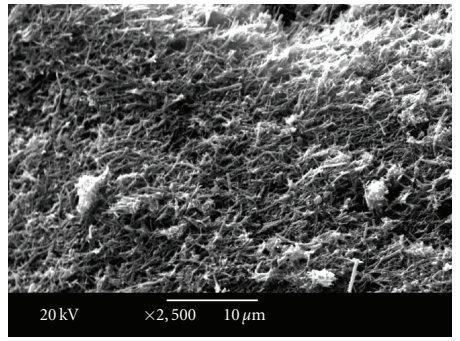

(b)

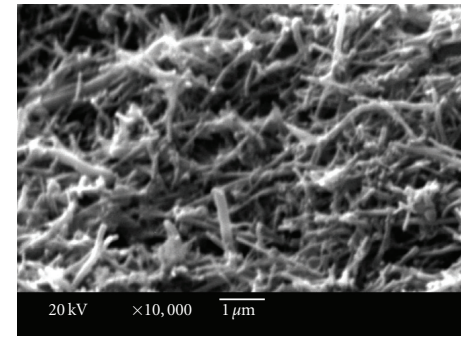

(c)

FIgURE 8: Micrographs of 15\% PR-19-PS TPUN cross section in progressive magnifications.

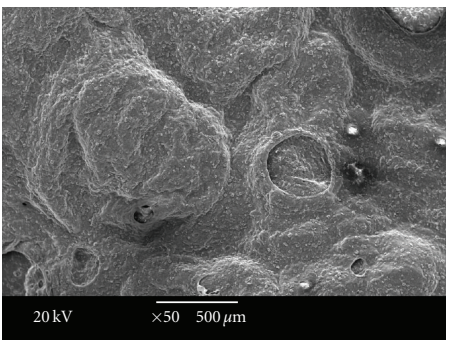

(a)

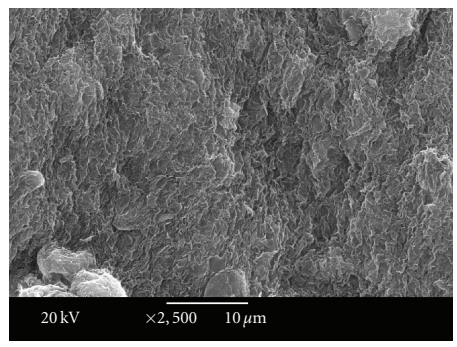

(b)

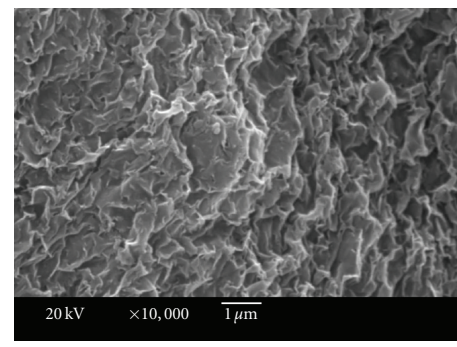

(c)

Figure 9: Micrographs of 5\% Cloisite 30B TPUN surface in progressive magnifications.

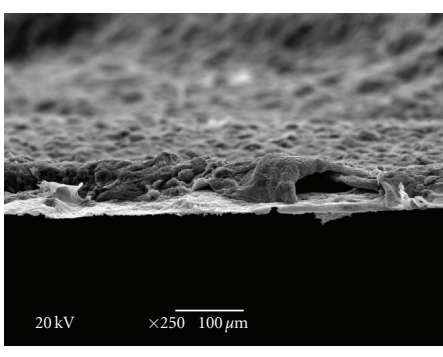

(a)

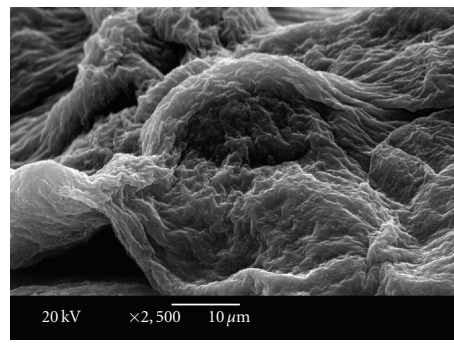

(b)

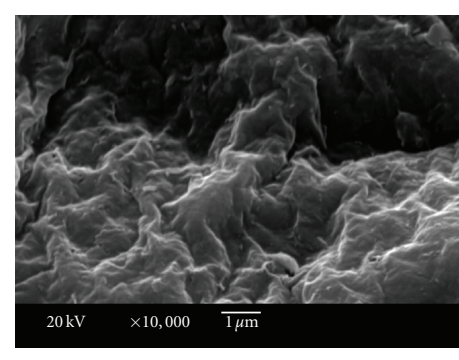

(c)

FIGURE 10: Micrographs of 5\% Cloisite 30B TPUN cross section in progressive magnifications.

isothermally for 5 minutes, and then cooled from $400^{\circ} \mathrm{C}$ to room temperature at cooling rate of approximately $200^{\circ} \mathrm{C} /$ hour [23]. Figures 9 and 10 show the SEM micrographs of the surface and cross section, respectively, of the 5\% Cloisite 30B TPUN at progressive magnifications. On the surface, compared to the PR-19-PS TPUN samples, a relatively smaller number and sizes of fractured bubble traces are observed, and premature char layers are formed (Figure 9). Figure 10 shows the SEM micrographs of cross section of $5 \%$ Cloisite $30 \mathrm{~B}$ TPUN. At $400^{\circ} \mathrm{C}$, the material is undergoing the pyrolysis reaction. There is still a relatively large amount of resin remaining in the material. These SEM micrographs show the comparison of material thickness at two different heating temperatures, about $100 \mu \mathrm{m}$ thick at $400^{\circ} \mathrm{C}$ and about $1 \mu \mathrm{m}$ at $600^{\circ} \mathrm{C}$. This difference can be explained by observing the weight loss data in TGA experiments [23]. Reaction terminates in the proximity of $550^{\circ} \mathrm{C}$ and no additional significant weight loss is observed.
The composite structure consists of only char at $600^{\circ} \mathrm{C}$, while it is composed of virgin, degrading resin, and char components at $400^{\circ} \mathrm{C}$.

Figures 11 and 12 show the SEM micrographs of the surface and cross-section of 15\% PR-19-PS TPUN, respectively, at progressive magnifications. Numerous bubbles are distributed across the entire surface, many of which are not yet burst. The critical internal pressure has not been attained for fracture. The micrographs of the cross section show clearly that the material is undergoing thermal expansion. Diameter of the bubbles is in the scale of $500 \mu \mathrm{m}$. Some resin is still intact on the CNFs networks.

3.2.3. Thermal Conductivity. Thermal conductivity was derived based on the relationship: $k=\alpha(T) \rho(T) c_{p}(T)$, where $k$ is thermal conductivity, $\alpha$ is thermal diffusivity, $\rho$ is density, and $c_{p}$ is specific heat. All thermophysical properties data were tabulated in Table $2[20,24]$. Both the 5\% Cloisite 
TABLE 2: Thermophysical properties of TPU and TPUNs (at $45^{\circ} \mathrm{C} /$ at $55^{\circ} \mathrm{C}$ ).

\begin{tabular}{lcccc}
\hline Material & Density $(\mathrm{g} / \mathrm{cc})$ & $\begin{array}{c}\text { Specific heat } \\
\left(\mathrm{J} / \mathrm{g}-{ }^{\circ} \mathrm{C}\right)\end{array}$ & $\begin{array}{c}\text { Thermal } \\
\text { diffusivity } \\
\left(10^{-7} \mathrm{~m}^{2} / \mathrm{s}\right)\end{array}$ & $\begin{array}{c}\text { Thermal } \\
\text { conductivity } \\
\left(\mathrm{W} / \mathrm{m}-{ }^{\circ} \mathrm{C}\right)\end{array}$ \\
\hline 2102-90A TPU & 1.18 & $1.514 / 1.524$ & $1.133 / 1.007$ & $0.202 / 0.180$ \\
$5 \%$ Cloisite 30B TPUN & 1.21 & $1.814 / 1.886$ & $1.087 / 1.057$ & $0.239 / 0.241$ \\
$15 \%$ PR-19-PS TPUN & 1.27 & $1.473 / 1.491$ & $1.583 / 1.523$ & $0.296 / 0.288$ \\
\hline
\end{tabular}

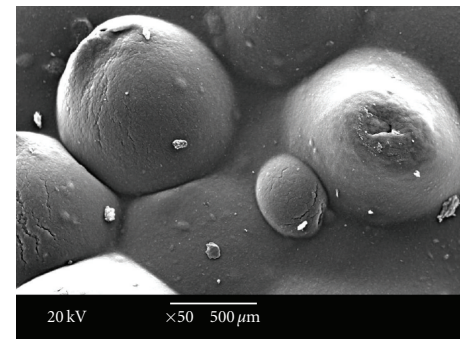

(a)

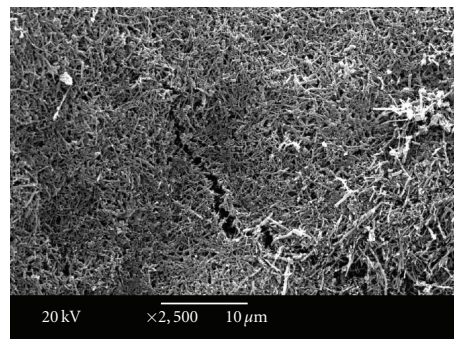

(b)

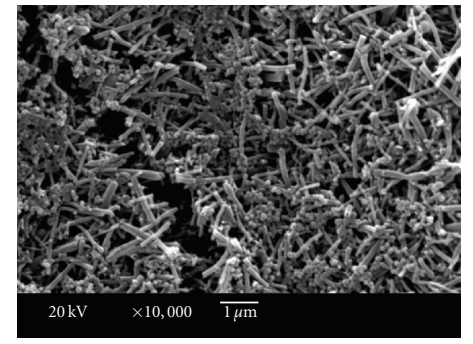

(c)

FIGURE 11: Micrographs of 15\% PR-19-PS TPUN surface in progressive magnifications.

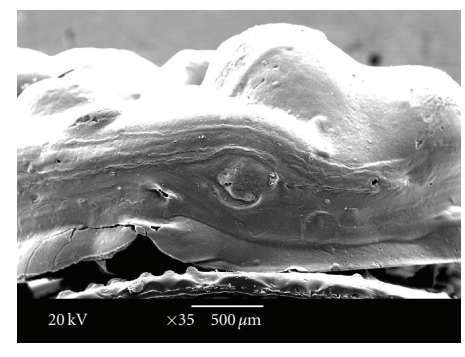

(a)

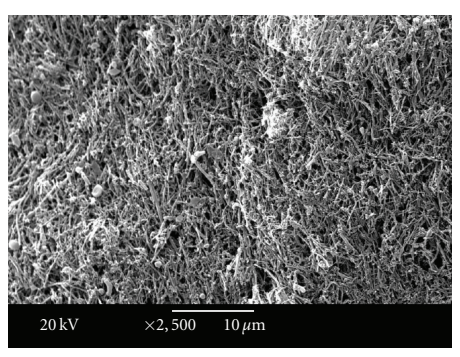

(b)

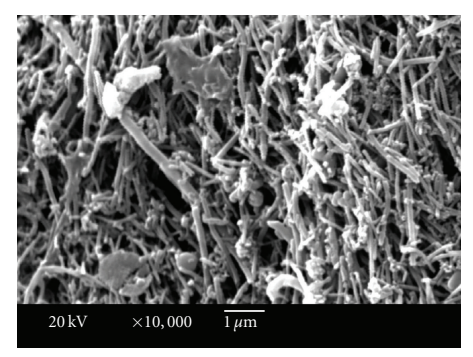

(c)

FIGURE 12: Micrographs of 15\% PR-19-PS TPUN cross section in progressive magnifications.

30B TPUN (TPUN-clay) and 15\% PR-19-PS TPUN (TPUN$\mathrm{CNF}$ ) have higher densities than the neat TPU. The specific heat of the TPUN-clay is substantially higher than the neat TPU, while the TPUN-CNF is lower than the neat TPU. The thermal conductivity values of both the TPUN-clay and TPUN-CNF are higher than the neat TPU, with the carbonbased TPUN-CNF substantially more thermally conductive than the neat TPU. All these thermophysical properties need to be characterized in the charred state at elevated temperatures for our numerical modeling research [25].

3.2.4. Flammability Studies. Flammability properties of these TPUNs materials were measured to access the dual commercial usage of this family of novel materials developed mainly for military application. In this study, 5\% PR-19PS TPUN instead of 15\% PR-19-PS TPUN was tested under a radiant heat flux of $50 \mathrm{~kW} / \mathrm{m}^{2}$. Two samples of each formulation were tested for repeatability. The TPUNs were compared with the pure TPU 2102-90A. Average flammability properties were summarized in Table $3[20,24]$.
From the flammability data, the 5\% Cloisite $30 \mathrm{~B}$ nanoclay had slightly increased the time to sustained ignition (34 seconds) to the baseline 2102-90A TPU (32 seconds). The 5\% PR-19-PS CNF had a slightly adverse effect on the 2102-90A TPU in terms of time to sustained ignition. The 5\% PR-19-PS CNF and the 5\% Cloisite 30B materials had a significant effect on the peak heat release rate (PHRR) of the TPU with a $73 \%$ reduction of PHHR $\left(624 \mathrm{~kW} / \mathrm{m}^{2}\right)$ for the 5\% PR-19-PS CNF material and a $71 \%$ reduction of PHHR $\left(644 \mathrm{~kW} / \mathrm{m}^{2}\right)$ for the $5 \%$ Cloisite $30 \mathrm{~B}$ material as compared to the $2102-90 \mathrm{~A}$ TPU $\left(2,290 \mathrm{~kW} / \mathrm{m}^{2}\right)$. The TPUNs had lower average HRR at 180 seconds and lower average effective heat of combustion than the TPU. Figure 13 shows the HRRs of these three materials. Figure 14 shows the mass remaining percentages of the materials. Both TPUNs had lower mass loss rates for the initial 150 seconds and experienced higher mass loss rates than the baseline material after 150 seconds. The peak CO concentrations (Figure 15) and the peak smoke concentration (Figure 16) of the TPUNs were significantly lower than 2102-90A TPU. 
TABLE 3: Summary of cone calorimetry data at irradiance heat flux of $50 \mathrm{~kW} / \mathrm{m}^{2}$.

\begin{tabular}{|c|c|c|c|c|c|c|}
\hline Material & $\mathrm{t}_{\mathrm{ig}}(\mathrm{s})$ & $\operatorname{PHRR}\left(\mathrm{kW} / \mathrm{m}^{2}\right)$ & $\begin{array}{c}\text { Avg. HRR, } 60 \\
\text { seconds } \\
\left(\mathrm{kW} / \mathrm{m}^{2}\right) \\
\end{array}$ & $\begin{array}{c}\text { Avg. HRR, } 180 \\
\text { seconds } \\
\left(\mathrm{kW} / \mathrm{m}^{2}\right)\end{array}$ & $\begin{array}{c}\text { Avg. Eff. } \mathrm{H}_{\mathrm{c}} \\
(\mathrm{MJ} / \mathrm{kg})\end{array}$ & $\begin{array}{c}\text { Avg. SEA } \\
\left(\mathrm{m}^{2} / \mathrm{kg}\right)\end{array}$ \\
\hline 2102-90A TPU & 32 & 2290 & 406 & 653 & 30 & 237 \\
\hline 5\% Cloisite 30B TPUN & 34 & $\begin{array}{l}664(71 \% \\
\text { reduction) }\end{array}$ & 560 & 562 & 25 & 303 \\
\hline 5\% PR-19-PS TPUN & 27 & $\begin{array}{c}624(73 \% \\
\text { reduction) }\end{array}$ & 532 & 456 & 22 & 295 \\
\hline
\end{tabular}

$\mathrm{t}_{\mathrm{ig}}$ : Time to sustained ignition; PHHR: Peak heat release rate; Avg. HRR: Average heat release rate after ignition; Avg. Eff, $\mathrm{H}_{\mathrm{c}}$ : Effective heat of combustion; Avg. SEA: Average specific extinction area.

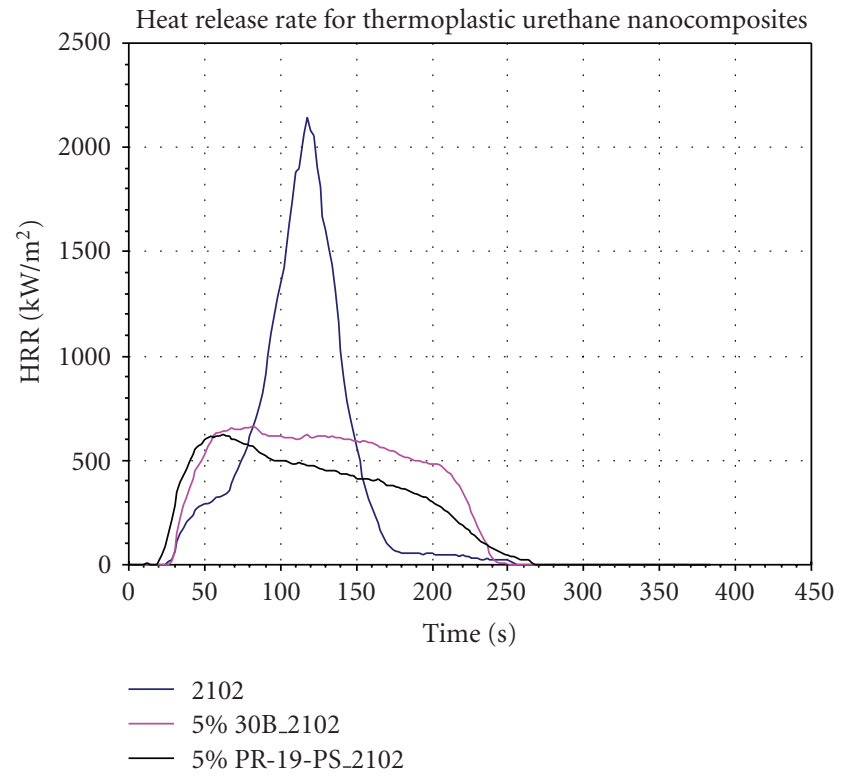

FIGURE 13: Heat release rates of 2102-90A TPU and TPUNs.

The low smoke and CO concentration features also made the TPUNs a very attractive class of fire retardant polymers that has potential to be used for commercial markets.

\section{Conclusions}

Formulations of TPU with 5\% Cloisite 30B nanoclay and 15\% PR-19-PS carbon nanofibers were compounded via twin-screw extrusion. TEM and WAXD results confirmed that the nanoclays were fully exfoliated in the TPU, and TEM results showed that the carbon nanofibers were well dispersed in the polymer. Precharring of TPUNs was performed to study their char characteristics using SEM. It was believed that the nanoclay platelets remained in the pyrolysis zone when the polymer was consumed under intense heat and formed a ceramic shield-like structure (protective mechanism) to insulate the virgin material. As the virgin material degraded on the top layer, the nanoclay platelets collapsed through the depth of the material, resulting in a much thinner specimen compared to the virgin specimen.

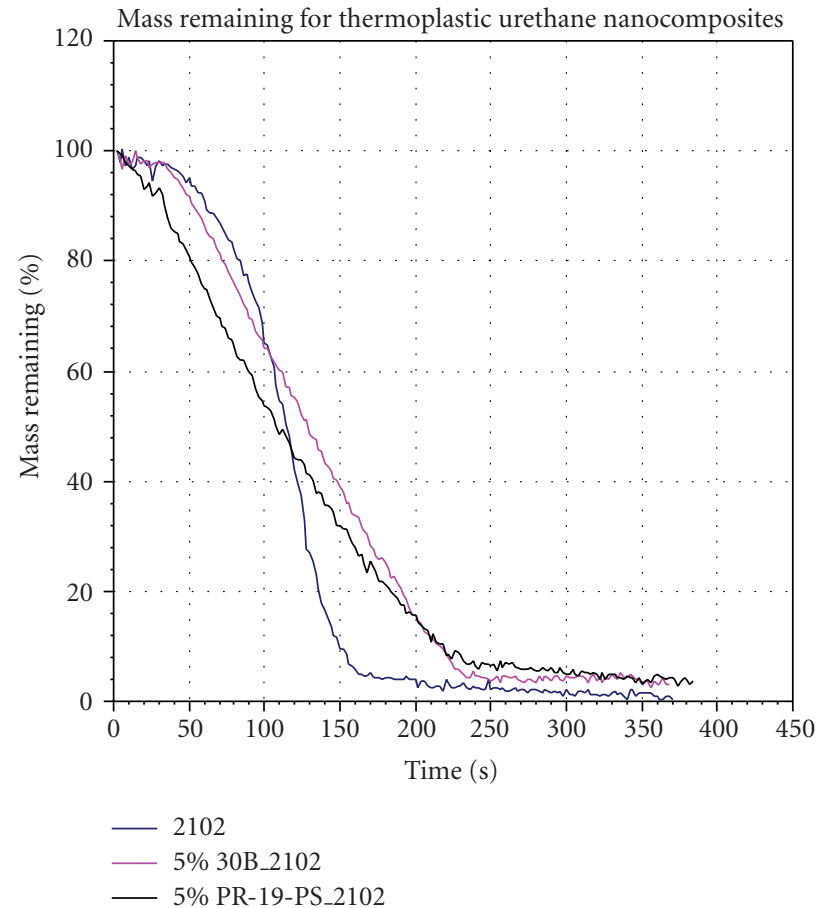

Figure 14: Mass loss of 2102-90A TPU and TPUNs.

Large fractured bubbles on the surface and cross section of carbon nanofiber specimen were observed. Networks of carbon nanofibers (protective mechanism) were identified at high magnifications, and their porous structure assisted in reducing the heat transfer through the material. In addition, the integrity of TPUN-clay specimen was maintained after charring at $600^{\circ} \mathrm{C}$, but that of TPUN-CNF specimen did not. Neat TPU specimen was completely consumed at $600^{\circ} \mathrm{C}$, and thus no char or residue was collected.

Both the TPUN-clay and TPUN-CNF have higher densities than the neat TPU. The specific heat of the TPUNclay is substantially higher than the neat TPU, while the TPUN-CNF is lower than the neat TPU. The thermal conductivities of both the TPUN-clay and TPUN-CNF are higher than the neat TPU, with the carbon-based TPUNCNF substantially more thermally conductive than the neat TPU. The characterization of these properties will provide 


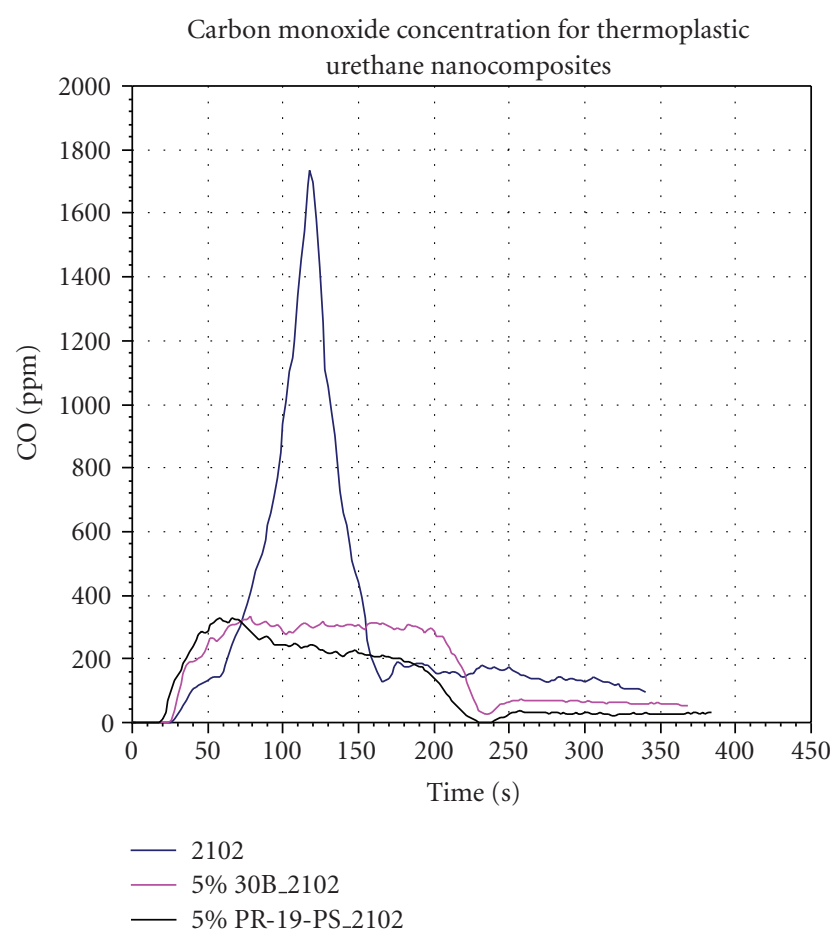

FIGURE 15: Carbon monoxide concentration of 2102-90A TPU and TPUNs.

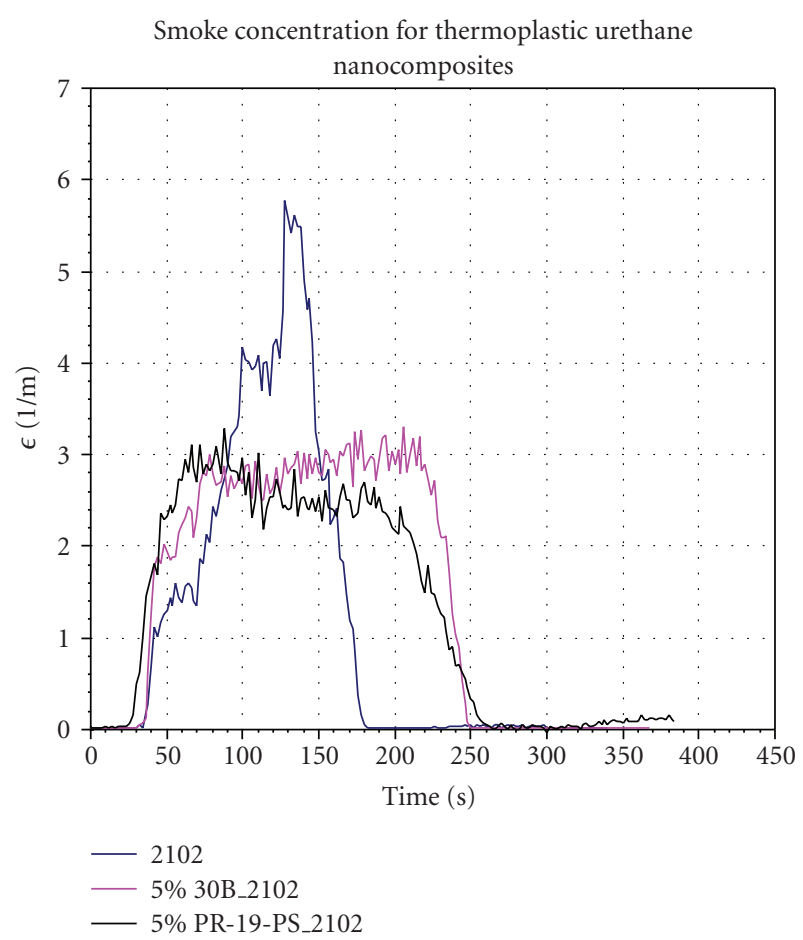

Figure 16: Smoke concentration of 2102-90A TPU and TPUNs.

a better understanding of the thermal response of the material. Continuation of this research will include the proper method of precharring and tailoring the material for charred material properties measurements. Once these thermophysical properties are obtained, they are expected to be extrapolated to higher temperatures. Then, these properties will be used in a numerical model [25] to predict the material behavior at a higher heat flux that simulates a solid rocket motor environment.

Cone calorimetry data show that the nanofillers significantly reduced the peak heat release rate of the neat TPU. In addition, carbon monoxide and smoke concentrations of the TPUNs were also significantly lower than the neat TPU. If nanofiller have synergistic effect with conventional fire retardant additive, it may reduce the amount of conventional FR additives needed by the polymer to be less flammable. This study demonstrated that the TPUNs developed primary for military usage as internal insulation materials for solid rocket motor can be extended for commercial usage as flame retardant materials.

\section{Acknowledgments}

The authors would like to acknowledge Dr. C. Y-C. Lee of AFOSR for sponsoring this project through Contract no. FA9550-06-1-0356. The authors would also like to thank Dr. Ly at Aerojet for precharring the TPUNs and Dr. Blanski and colleagues at Air Force Research Laboratory/Edwards $\mathrm{AFB}, \mathrm{CA}$, for conducting the thermophysical properties measurements. The authors also thank Dr. Luo at Texas A\&M University/Microscopy and Imaging Center for conducting the TEM analyses and Dr. Wissler at 21st Century Polymers for compounding the TPUNs.

\section{References}

[1] J. H. Koo, D. W. H. Ho, and O. A. Ezekoye, "A review of numerical and experimental characterization of thermal protection materials_-part I: numerical modeling," in Proceedings of the 42nd AIAA/ASME/SAE/ASEE Joint Propulsion Conference, vol. 8, pp. 5895-5945, AIAA, Reston, Va, USA, 2006, AIAA Paper 2006-4936.

[2] J. H. Koo, D. W. H. Ho, M. C. Bruns, and O. A. Ezekoye, "A review of numerical and experimental characterization of thermal protection materials-part II: properties characterization," in Proceedings of the AIAA/ASME/ASCE/AHS/ASC Structures, Structural Dynamics and Materials Conference, pp. 5136-5175, AIAA, Reston, Va, USA, 2007, AIAA Paper 20072131.

[3] D. W. K. Ho, J. H. Koo, M. C. Bruns, and O. A. Ezekoye, "A review of numerical and experimental characterization of thermal protection materials_-part III: experimental testing," in Proceedings of the 43rd AIAA/ASME/SAE/ASEE Joint Propulsion Conference, vol. 8, pp. 7524-7598, AIAA, Reston, Va, USA, 2007, AIAA Paper 2007-5773.

[4] T. J. Pinnavaia and G. W. Beall, Eds., Polymer-Clay Nanocomposites, John Wiley \& Sons, New York, NY, USA, 2000.

[5] J. H. Koo, Polymer Nanocomposites: Processing, Characterization, and Applications, McGraw-Hill, New York, NY, USA, 2006.

[6] A. B. Morgan and C. A. Wilkie, Eds., Flame Retardant Polymer Nanocomposites, John Wiley \& Sons, Hobken, NJ, USA, 2007.

[7] S. N. Bhattacharya, R. K. Gupta, and M. R. Kamal, Polymeric Nanocomposites: Theory and Practice, Hanser Gardner, Cincinnati, Ohio, USA, 2008. 
[8] R. A. Vaia, G. Price, P. N. Ruth, H. T. Nguyen, and J. Lichtenhan, "Polymer/layered silicate nanocomposites as high performance ablative materials," Applied Clay Science, vol. 15, no. 1-2, pp. 67-92, 1999.

[9] R. D. Patton, C. U. Pittman Jr., L. Wang, J. R. Hill, and A. Day, "Ablation, mechanical and thermal conductivity properties of vapor grown carbon fiber/phenolic matrix composites," Composites A, vol. 33, no. 2, pp. 243-251, 2002.

[10] J. H. Koo, H. Stretz, A. Bray, et al., "Nanostructured materials for rocket propulsion system: recent progress," in Proceedings of the AIAA/ASME/ASCE/AHS/ASC Structures, Structural Dynamics and Materials Conference, pp. 3351-3361, AIAA, Reston, Va, USA, 2003, AIAA Paper 2003-1769.

[11] J. H. Koo, H. Stretz, J. T. Weispfenning, Z. Luo, and W. Wootan, "Nanocomposite rocket ablative materials: processing, microstructure, and performance," in Proceedings of the AIAA/ASME/ASCE/AHS/ASC Structures, Structural Dynamics and Materials Conference, pp. 5090-5104, AIAA, Reston, Va, USA, 2004, AIAA Paper 2004-1996.

[12] J. H. Koo and L. A. Pilato, "Thermal properties and microstructures of polymer nanostructured materials," in Nanoengineering of Structural, Functional, and Smart Materials, M. J. Schulz, A. Kelkar, and M. J. Sundaresan, Eds., pp. 409-441, CRC Press, Boca Raton, Fla, USA, 2006.

[13] J. H. Koo, L. A. Pilato, and G. E. Wissler, "Polymer nanostructured materials for propulsion systems," Journal of Spacecraft and Rockets, vol. 44, no. 6, pp. 1250-1262, 2007.

[14] J. H. Koo, in Polymer Nanocomposites: Processing, Characterization, and Applications, pp. 10-19, McGraw-Hill, New York, NY, USA, 2006.

[15] J. H. Koo, in Polymer Nanocomposites: Processing, Characterization, and Applications, pp. 19-26, McGraw-Hill, New York, NY, USA, 2006.

[16] Z. P. Luo and J. H. Koo, "Quantifying the dispersion of mixture microstructures," Journal of Microscopy, vol. 225, no. 2, pp. 118-125, 2007.

[17] Z. P. Luo and J. H. Koo, "Quantification of the layer dispersion degree in polymer layered silicate nanocomposites by transmission electron microscopy," Polymer, vol. 49, no. 7, pp. 1841-1852, 2008.

[18] Z. P. Luo and J. H. Koo, "Quantitative study of the dispersion degree in carbon nanofiber/polymer and carbon nanotube/polymer nanocomposites," Materials Letters, vol. 62, no. 20, pp. 3493-3496, 2008.

[19] W. K. Ho, J. H. Koo, J. C. Lee, and O. A. Ezekoye, "Thermophysical properties characterization of thermoplastic polyurethane elastomer nanocomposites," in Proceedings of the 44nd AIAA/ASME/SAE/ASEE Joint Propulsion Conference, AIAA, Reston, Va, USA, 2008, AIAA Paper 2008-5146.

[20] D. W. K. Ho, J. H. Koo, and O. A. Ezekoye, "Kinetics and thermophysical properties of polymer nanocomposites for solid rocket motor insulation," Journal of Spacecraft and Rockets, vol. 46, no. 3, pp. 526-544, 2009.

[21] R. Blanksi, J. H. Koo, P. Ruth, H. Nguyen, C. Pittman, and S. Phillips, "Polymer nanostructured materials for solid rocket motor insulation-ablation performance," in Proceedings of the 52nd JANNAF Propulsion Meeting (CPIAC '04), Columbia, Md, USA, May 2004.

[22] J. B. Henderson, An analytical and experimental study of the pyrolysis of composite ablative materials, Ph.D. dissertation, Oklahoma State University, Stillwater, Okla, USA, 1980.
[23] W. K. Ho, Determination of kinetic parameters and char microstructural analysis of thermoplastic polyurethane elastomer nanocomposites for propulsion systems, M.S. thesis, Department of Mechanical Engineering, The University of Texas at Austin, Austin, Tex, USA, December 2007.

[24] D. Marchant, J. H. Koo, R. L. Blanski, et al., "Flammability and thermophysical characterization of thermoplastic elastomer nanocomposites," in Proceedings of the 228th ACS National Meeting, Fire and Polymers Symposium, Philadelphia, Pa, USA, 2004.

[25] M. C. Bruns, J. H. Koo, and O. A. Ezekoye, "Population-based models of thermoplastic degradation: using optimization to determine model parameters," Polymer Degradation and Stability, vol. 94, no. 6, pp. 1013-1022, 2009. 

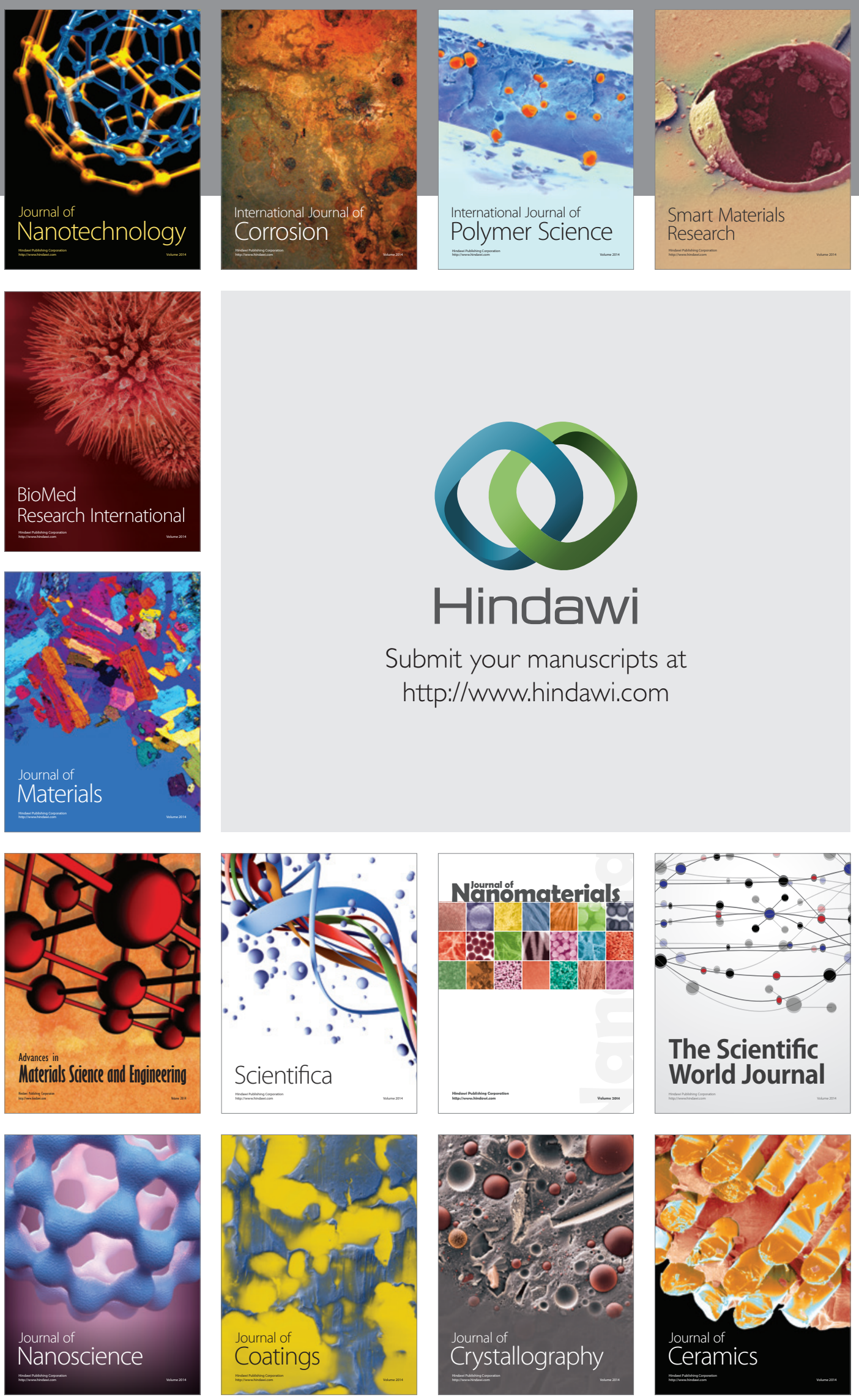

The Scientific World Journal

Submit your manuscripts at

http://www.hindawi.com

\section{World Journal}

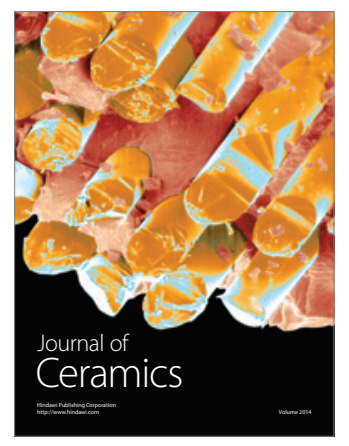

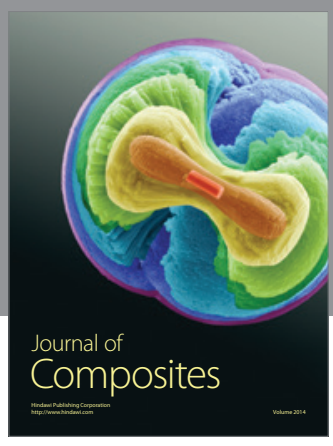
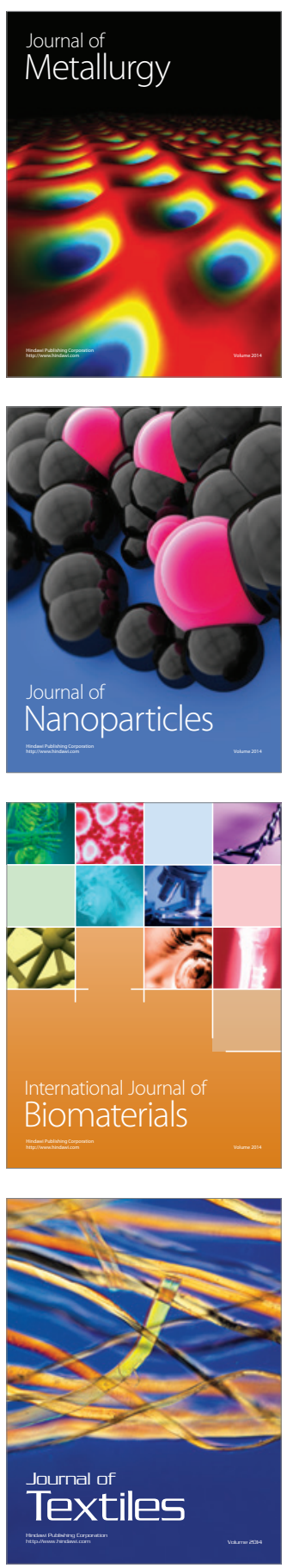